\title{
Psoriasis Gutata - Laporan Kasus
}

\author{
${ }^{1}$ Julieta D. P. Dotulong, ${ }^{1}$ Charly M. M. Korompis, ${ }^{2}$ Herry E. J. Pandaleke
}

\author{
${ }^{1}$ PPDS Ilmu Kesehatan Kulit dan Kelamin Fakultas Kedokteran Universitas Sam Ratulangi \\ Manado \\ ${ }^{2}$ Bagian Ilmu Kesehatan Kulit dan Kelamin Fakultas Kedokteran Universitas Sam Ratulangi \\ Manado \\ Email: julietadotulong@gmail.com
}

\begin{abstract}
Guttate psoriasis (GP) is a variant of psoriasis with typical drop-shaped lesions sized $0.5-1 \mathrm{~cm}$ in diameter, localized especially in the upper part of the body and proximal extremities. It usually occurs in young adult. We reported a female, 11 years old, with red, itchy, and scaly patches distributed nearly all over the body. There was a history of sore throat. Dermatologic status showed multiple erythematous plaques which were miliar to numular, discrete, and were covered with layered silvery white scales. The Auspitz sign, wax spot phenomenon, and ASTO were positive. The histopathologic examination showed parakeratosis and Munro microabcesses. The patient treated with topical steroid for 4 weeks made improvement. Conclusion: In this case, diagnosis of guttate psoriasis was based on anamnesis, examination, and supporting examinations. Streptococcal infection was suspected as the trigger factor due to the positive ASTO examination. Topical steroid as the first line therapy for mild to moderate psoriasis made great improvement.
\end{abstract}

Keywords: guttate psoriasis, streptococcal infection

\begin{abstract}
Abstrak: Psoriasis gutata (PG) merupakan varian dari psoriasis. Gambaran khasnya seperti tetesan air dengan diameter $0,5-1 \mathrm{~cm}$, di badan bagian atas dan ekstremitas proksimal. Sering terjadi pada dewasa muda. Kami melaporkan kasus seorang perempuan berusia 11 tahun dengan bercak merah meninggi, bersisik, disertai gatal pada hampir seluruh tubuh. Riwayat nyeri menelan positif. Riwayat pengobatan sebelumnya disangkal. Status dermatologis ditemukan plak eritem, multipel, miliar-numular, diskret, ditutupi skuama berlapis warna putih keperakan. Pemeriksaan tanda Auspitz, fenomena bercak lilin, dan ASTO positif. Pada pemeriksaan histopatologik didapatkan adanya parakeratosis dan mikroabses Munro. Terapi steroid topikal potensi tinggi selama 4 minggu menunjukkan perbaikan. Simpulan: Pada kasus ini diagnosis psoriasis gutata ditegakkan berdasarkan anamnesis, pemeriksaan fisik, dan pemeriksaan penunjang yang khas. Infeksi streptokokus diduga sebagai faktor pencetus berdasarkan hasil pemeriksaan ASTO. Terapi steroid topikal merupakan lini pertama untuk psoriasis ringan sampai sedang memperlihatkan perbaikan yang nyata.
\end{abstract}

Kata kunci: psoriasis gutata, infeksi streptokokus

Psoriasis gutata (PG) merupakan varian dari psoriasis dengan gambaran klinis yang khas berupa bercak merah meninggi seperti tetesan air dengan diameter berukuran kecil yang biasanya tidak melebihi $1 \mathrm{~cm}$, timbul mendadak dan diseminata. ${ }^{1,2}$ Umumnya timbul setelah infeksi streptokokus di saluran napas bagian atas. 2,3
Psoriasis gutata sering terjadi pada anak-anak dan dewasa muda. ${ }^{1,2}$ Prevalensi psoriasis gutata di Eropa pada umur 0-9 tahun berkisar antara 0,37\%-0,55\% sedangkan pada umur 10-19 tahun berkisar antara 1,01\%-1,37\%. ${ }^{4}$ Di RSUP Prof. Dr. R. D. Kandou Manado pada bulan JanuariDesember 2012 jumlah kasus psoriasis 
gutata didapatkan sebanyak 7 kasus dari total 48 kasus psoriasis dan jumlah pasien psoriasis gutata pada anak ialah 2 dari 7 kasus psoriasis gutata. $^{5}$ Angka kejadian psoriasis gutata pada anak di Indonesia memang tidak banyak dilaporkan.

Gambaran klinis psoriasis gutata berupa plak berwarna merah muda berukuran kecil seperti tetesan air dengan diameter $0,5-1 \mathrm{~cm}^{1,3}$ Pada stadium awal biasanya disertai sedikit skuama dengan ukuran diameter lesi dari 0,2-1 cm, berbentuk bulat atau sedikit oval, ${ }^{6}$ kemudain menyebar diskret secara sentripetal terutama di badan bagian atas, ekstremitas proksimal, wajah, telinga, dan kepala. Biasanya diawali dengan infeksi streptokokus beta hemolitikus dalam bentuk faringitis, laringitis atau tonsilitis. ${ }^{2,4}$ Pemeriksaan penunjang yang dibutuhkan untuk menegakkan diagnosis PG, antara lain: fenomena bercak lilin, Auspitz sign, fenomena Koebner, pemeriksaan anti-streptolysin titer $O$ (ASTO), dan pemeriksaan histopatologik.,

Terapi topikal untuk PG merupakan pilihan terapi pertama untuk psoriasis ringan dan sedang, dan juga dianggap aman bagi anak. $^{7}$

Prognosis kasus PG ialah quo ad vitam, quo ad functionam ad bonam, quo ad sanationam dubia ad bonam. ${ }^{1}$

Berikut ini dilaporkan satu kasus psoriasis gutata pada seorang anak.

\section{LAPORAN KASUS}

Seorang anak perempuan berusia 11 tahun datang ke Poliklinik Kulit dan Kelamin RSUP Prof. Dr. R.D kandou Manado dengan keluhan bercak merah meninggi seukuran biji jagung sampai sebesar uang logam di daerah wajah, badan, lengan, dan paha sejak 1 minggu yang lalu. Awalnya timbul bercak-bercak merah meninggi di daerah perut yang kemudian dalam beberapa hari jumlahnya bertambah banyak dan menyebar ke hampir seluruh tubuh. Bercak-bercak merah meninggi tersebut disertai sisik berwarna putih yang terasa gatal. Sebelumnya 2 minggu yang lalu pasien sempat mengeluh batuk, pilek disertai nyeri menelan.
Pada pemeriksaan fisik ditemukan keadaan umum baik, tanda-tanda vital dalam batas normal, dan indeks massa tubuh dalam batas normal. Pada status dermatologis di regio facialis, thoracalis anterior et posterior, regio brachii et antebrachii dextra et sinistra, regio femoralis et cruris dextra et sinistra ditemukan plak eritematosa, batas tegas, multipel, ukuran miliar-numular, diskret, ditutupi skuama putih keperakan (Gambar 1). Pemeriksaan fenomena bercak lilin dan Auspitz sign memberikan hasil positif.

Pemeriksaan serologik ASTO untuk menentukan faktor pencetus terjadinya psoriasis antara lain karena infeksi streptokokus beta hemolitikus. Pada kasus ini didapatkan hasil ASTO positif. Pada pemeriksaan histopatologik didapatkan suatu psoriasis gutata dengan gambaran hiperkeratosis dan parakeratosis pada epidermis dengan adanya abses Munro.

Penatalaksanaaan psoriasis gutata meliputi nonmedikamentosa dengan memberikan informasi tentang penyakit dan faktor-faktor pencetusnya, menjelaskan tentang pengobatan yang diberikan dan edukasi kemungkinan penyakit dapat timbul kembali setelah terapi. Penatalaksanaan medikamentosa dengan cetirizine tablet $10 \mathrm{mg} 1 \times 1 \mathrm{tab}$, hidrokortison krim 2 xoles pada wajah, desoksimetasone krim 2xoles di badan, emolien, dan mandi dengan sabun bayi. Pada hari ke-5 tampak lesi mulai membaik dan tidak terdapat lesi baru (Gambar 2). Pada minggu ke-4 terapi menunjukkan perbaikan yang optimal, dan sudah tidak tampak lesi (Gambar 3).

\section{BAHASAN}

Diagnosis psoriasis gutata (PG) ditegakkan berdasarkan anamnesis, pemeriksaan fisik, laboratorium dan pemeriksaan histopatologik.

Berdasarkan anamnesis diketahui pasien ialah anak perempuan berusia 11 tahun, dengan keluhan bercak-bercak merah meninggi seukuran biji jagung sampai sebesar uang logam di daerah wajah, badan, lengan dan paha sejak 1 minggu sebelum datang ke rumah sakit. 

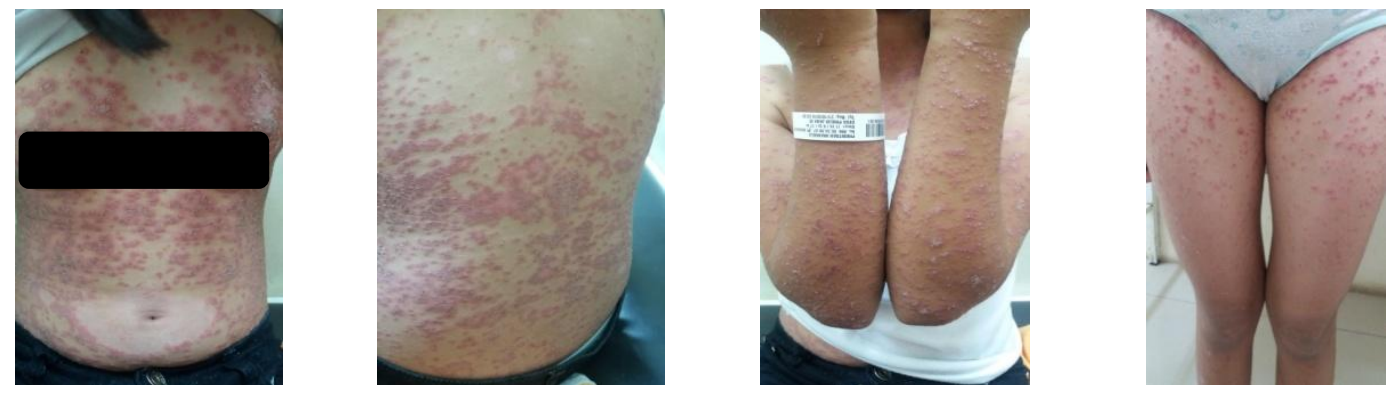

Gambar 1. Hari ke-1: tampak plak eritematosa, batas tegas, multipel, ukuran miliar-numular, diskret disertai skuama putih keperakan di daerah wajah, badan, lengan, dan paha
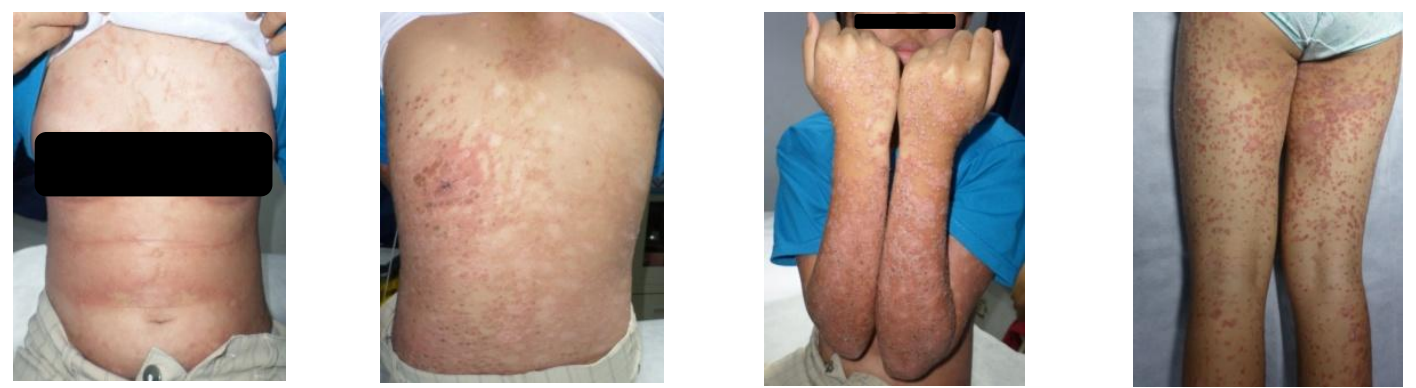

Gambar 2. Hari ke-5: lesi mulai membaik dan tidak terdapat lesi baru
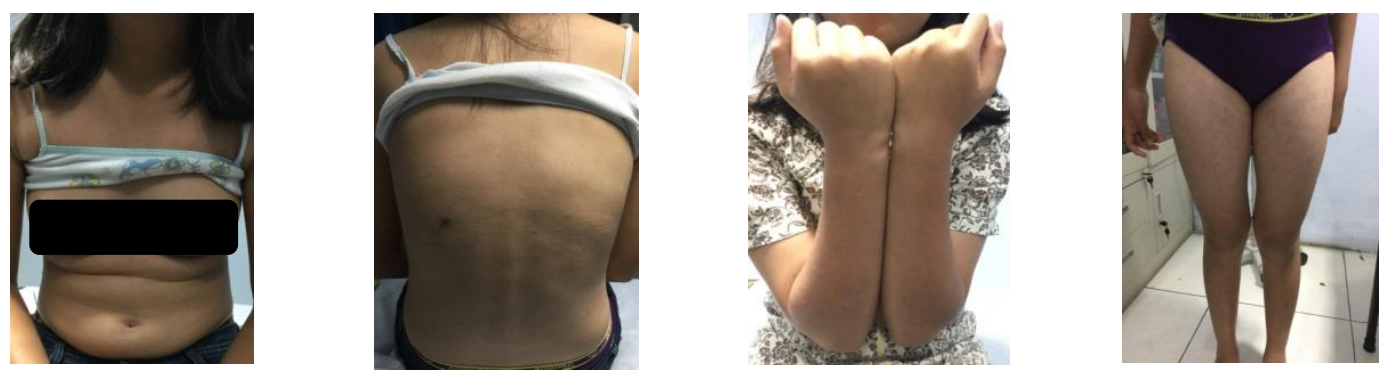

Gambar 3. Minggu ke-4: perbaikan optimal, kulit kembali normal

Awalnya timbul bercak merah kecil di daerah perut yang kemudian menyebar ke hampir seluruh tubuh. Bercak-bercak merah meninggi tersebut disertai sisik berwarna putih. Gatal dirasakan juga oleh pasien. Sebelumnya 2 minggu yang lalu pasien mengeluh batuk, pilek disertai nyeri menelan. Menurut acuan pustaka, PG sering terjadi pada anak-anak dan dewasa muda, serta dapat menyerang baik laki-laki maupun perempuan. ${ }^{8}$ Gambaran klinis PG awalnya berupa makula eritematosa berukuran kecil, kemudian ukurannya berkembang menjadi seperti tetesan air, berwarna merah muda dan menyebar secara sentripetal yang sering disertai gatal. ${ }^{1,3,4}$ Pada beberapa studi epidemiologis dinyatakan bahwa PG akut pada anak dapat berkem- bang menjadi psoriasis plakat. ${ }^{9}$ Lesi biasanya timbul mendadak dan terjadi setelah infeksi streptokokal pada saluran napas atas, seperti: faringitis, laringitis atau tonsilitis. ${ }^{1-4,7}$ Pada pemeriksaan fisik ditemukan plak eritem, batas jelas, multipel, ukuran miliar-numular, diskret, disertai skuama putih di wajah, badan, lengan dan tungkai. Menurut acuan pustaka, PG paling sering mengenai daerah badan, ekstremitas dan kepala. Lesi berupa plak eritem berukuran diameter $0,5-1 \mathrm{~cm}$, multipel, tersebar, diskret, disertai skuama putih keperakan seperti mika.,

Pada kasus ini, terdapat beberapa pemeriksaan penunjang yang dilakukan, seperti: fenomena bercak lilin, Auspitz sign, pemeriksaan ASTO, dan pemeriksaan 
histopatologik. Hasil yang didapat ialah fenomena bercak lilin dan Auspitz sign positif. Pada pemeriksaan serologik, didapatkan hasil pemeriksaan ASTO positif sedangkan IgE total dalam batas normal. Pada gambaran histopatologik kasus ini didapatkan adanya jaringan kulit dilapisi epidermis yang hiperkeratosis dan parakeratosis dengan abses Munro dan degenerasi hidrofilik sel basal. Pada epidermis juga tampak spongiosis ringan. Pada dermis superfisial tampak edematous disertai infiltrasi sel-sel radang limfosit. Menurut acuan pustaka, pemeriksaan penunjang yang dibutuhkan untuk diagnosis PG, antara lain: adanya fenomena bercak lilin, Auspitz sign dan fenomena Koebner pada lesi. ${ }^{7,10}$ Hasil ASTO positif menunjukkan bahwa dugaan adanya hubungan PG dengan infeksi streptokokus beta hemolitikus, sehingga kemungkinan faktor pencetus PG pada kasus ini ialah karena infeksi. ${ }^{1,6,7}$ Peningkatan IgE total merupakan petanda terjadinya reaksi alergi yang berhubungan dengan hipersensitivitas. ${ }^{11}$ Pada pemeriksaan histopatologik, gambaran psoriasis ialah tampak adanya massa sel epidermis meningkat 3-5 kali dan masih banyak dijumpai mitosis di atas lapisan basal. Tampak hiperkeratosis (penebalan lapisan korneum) dan parakeratosis (penipisan atau menghilangnya stratum granulosum), infiltrasi sel radang limfosit, makrofag, sel dendrit dan sel mast terdapat sekitar pembuluh darah. Gambaran spesifik psoriasis ialah mikroabses Munro yaitu bermigrasinya sel radang granulosit neutrofil ke epidermis (lapisan parakeratosis stratum korneum). ${ }^{1,2,12}$

Diagnosis banding pada kasus ini ialah pitiriasis rosea dan erupsi obat alergi. ${ }^{1,13,14}$ Diagnosis banding pitiriasis rosea dapat disingkirkan karena pada kasus ini tidak didapatkan adanya lesi inisial yang disebut herald patch. ${ }^{15}$ Selain itu, pada kasus ini terdapat adanya skuama tebal berlapis berwarna putih keperakan sehingga bercak lilin dan Auspitz sign positif. Berdasarkan acuan pustaka, pitiriasis rosea biasanya ditandai adanya makula eritematosa berbentuk oval dengan skuama tipis yang tersusun seperti pohon cemara pada daerah badan, lengan atas, serta tungkai atas. Sebagian besar kasus diawali dengan lesi inisial yang disebut herald patch. ${ }^{14,15}$ Erupsi obat alergi dapat disingkirkan, karena pada anamnesis tidak didapatkan adanya lesi pada telapak tangan dan telapak kaki. $^{16,17}$ Pada hasil laboratorium tidak ditemukan adanya peningkatan IgE total yang merupakan petanda terjadinya reaksi alergi akibat hipersensitivitas.

Pengobatan pada kasus ini ialah diberikan kortikosteroid topikal berupa hidrokortison krim 2,5\%, desoksimetason krim $0,25 \% 2 \mathrm{x}$ oles, emolien, dan cetirizine tablet $10 \mathrm{mg} 1 \mathrm{x} 1$ tab setiap hari. Pasien ini diberikan kortikosteroid topikal karena pengobatan topikal merupakan pilihan terapi pertama untuk psoriasis ringan/ sedang. ${ }^{7,9}$ Pilihan terapi dengan kortikosteroid potensi tinggi yaitu desoksimetason krim $0,25 \%$ untuk badan, tangan dan kaki, dan potensi rendah hidrokortison krim 2,5\% untuk wajah karena pemilihan sediaan bergantung pada lokasi lesi yang akan diterapi, usia dan keparahan pasien., 1,18 Biasanya untuk wajah diberikan potensi rendah, sedangkan untuk badan, tangan, dan kaki diberikan potensi tinggi. ${ }^{7}$ Selain itu, diberikan emolien yang bermanfaat untuk melembutkan dan menghaluskan stratum korneum dengan cara trapping sehingga menurunkan kecepatan hilangnya air transepidermal. ${ }^{19}$

Prognosis pada pasien ini ialah quo ad vitam, quo ad functionam ad bonam, quo ad sanationam dubia ad bonam karena pada pasien ini PG hilang dalam waktu sekitar 4 minggu setelah terapi. Menurut aacuan pustaka, PG biasanya akan hilang sendiri (self-limited) dalam 12-16 minggu tanpa pengobatan, namun rekurensi dapat terjadi jika ada faktor pencetus. Meskipun psoriasis tidak menyebabkan kematian tetapi bersifat kronis dan residif. ${ }^{1,4,10}$

\section{DAFTAR PUSTAKA}

1. Gudjonsson JE, Elder JT. Psoriasis. In: Wolff K, Goldsmith LA, Katz SI, Gilcherst BA, Paller AS, Leffel DJ, editors. Fitzpatrick's Dermatology in 
General Medicine (8th ed). New York: McGraw-Hill Co, 2012; p. 197-231.

2. Jacoeb TNA. Psoriasis. In: Menaldi SLSW, Bramono K, Indriatmi W, editors. Ilmu Penyakit Kulit dan Kelamin (7th ed). Jakarta: Balai penerbit FKUI, 2015; p. 213-21.

3. Panduan Layanan Klinis Dokter Spesialis Dermatologi dan Venereologi. Psoriasis. Jakarta: Perhimpunan Dokter Spesialis Kulit dan Kelamin Indonesia (PERDOSKI), 2014; p. 166-78.

4. Van de Kerkhof PCM, Nestle FO. Psoriasis. In: Bolognia JL, Jorizzo JL, Schaffer JU, editors. Dermatology (3rd ed). Beijing: Elsevier, 2012; p. 135-55.

5. Moningka A, Kandou R, Niode N. Profil psoriasis di Poliklinik Kulit dan Kelamin RSUP Prof. Dr. R. D. Kandou Manado tahun 2012. e-Cl. 2015;3(2): 646-50.

6. Griffiths CEM, Barker JNWN. Psoriasis. In: Burns T, Breathnach S, Cox N, Griffiths C, edditors. Rook's Textbook of Dermatology (8th ed). Oxford: Blackwell Publishing Ltd, 2010; p. 20.1-20.43.

7. Pedoman Tata Laksana Psoriasis dan Informed Consent. Kelompok Studi Psoriasis Indonesia. Jakarta: Perhimpunan Dokter Spesialis Kulit dan Kelamin Indonesia, 2014; p. 3-19.

8. James WD, Berger TG, Elston DM. Seborrheic dermatitis, psoriasis, recalcitrant palmoplantar eruptions, pustular dermatitis, and erythroderma. In: James WD, Berger TG, Elston DM, editors Andrew's Disease of the Skin (12th ed). Philadelphia: Elsevier, 2016; p. 187-95.

9. De Waard-van der spek FB, Oranje AP. Psoriasis. In: Irvine A, Hoeger P, Yan A, editors. Harper's Textbook of Pediatric Dermatology (3rd ed). Oxford: Blackwell Publishing Ltd, 2011; p. 80.1-80.7.
10. Global report on psoriasis. [cited $2017 \mathrm{Feb}$ 10]. Available from: http: //www. apps.who.int/iris/bitstream/10665/2044 17/1/9789241565189_eng.pdf

11. Sutedjo AY. Pemeriksaan imunoserologi. In: Mengenal Penyakit Melalui Hasil Pemeriksaan Laboratorium (Edisi revisi). Yogyakarta: Amara Books, 2012; p.121-31

12. Rapini RP. Eczematous and papulosquamous diseases. Practical Dermatopathology (2nd ed). Beijing: Elsevier, 2012; p. 52-4.

13. Johhston RB. Psoriasiform reaction pattern. In: Johnston RB, editor. Weedon's Skin Pathology Essentials. Madrid: Elsevier, 2012; p. 54-6.

14. The histopathology of psoriasis. .[cited 2017 Feb 21]. Available from: https: //www. ncbi.nlm.nih.gov/pubmed/17828343

15. Blauvelt A. Pityriasis rosea. In: Wolff $K$, Goldsmith LA, Katz SI, Gilcherst BA, Paller AS, Leffel DJ, editors. Fitzpatrick's Dermatology in General Medicine (8th ed). New York: McGraw-Hill Co, 2012; p. 458-62.

16. Panduan Layanan Klinis Dokter Spesialis Dermatologi dan Venereologi. Erupsi kulit akibat alergi obat. Jakarta: Perhimpunan Dokter Spesialis Kulit dan Kelamin Indonesia (PERDOSKI), 2014; p. 151-4.

17. Differential diagnosis of psoriasis. [cited 2017 March 15]. Available from: https:// www.ncbi.nlm.nih.gov/pubmed/17828 346

18. Krueger GG, Duffin KC. Topical agents in the treatment of moderate to severe psoriasis. In: Koo JYM, Lee CS, et al, editors. Moderate-to-severe Psoriasis (3rd ed). New York; Informa Healthcare USA, 2001; p. 49-68.

19. Greaves MW. Antihistamines. In: Wolverton SE. Comprehensive Dermatologic Drug Therapy (3rd ed). Beijing: Elsevier, 2013; p. 343-50. 